\title{
HISTORIA, MEMORIA Y IMPUNIDAD: EL CASO DE IRMA FLAQUER
}

\section{Resumo}

\author{
June Carolyn Erlick
}

Universidade de Harvard - EUA

Na Guatemala, talvez mais do que em qualquer outro país, as comissões de investigação da verdade enfatizaram as narrativas de testemunho como documentos sobre os abusos do passado. No entanto, esta documentação manteve seu foco nas vítimas e nos crimes cometidos contra elas. A recuperação da vida das vítimas através da narrativa se apresenta como uma outra maneira de restaurar a memória e transformá-la em história. A vida e a obra da corajosa jornalista guatemalteca, Irma Flaquer, foi documentada pelo projeto da American Press Association, "Crimes Impunes contra Jornalistas." Como resultado, sob os auspícios da Comissão Interamericana dos Direitos Humanos, o governo da Guatemala admitiu sua responsabilidade no desaparecimento da jornalista e reabriu o caso. Assim, a reconstrução da memória através das técnicas narrativas não resultou apenas na reconstrução da história, mas em sua mudança.

\section{Pallavras-Chave}

Direitos Humanos • Guatemala • Jornalismo

\section{Abstract}

In Guatemala, perhaps more than in any other country, truth commissions emphasized narrative testimony to document the abuses of the past. However, this documentation has focused on the victims and the crimes against them. The recuperation of the lives of the victims through narrative is another way to restore memory and transform it into history. The life and work of Irma Flaquer, a courageous Guatemalan journalist, were documented as part of the Inter American Press Association's Unpunished Crimes Against Journalists project, As a result, under the auspices of the Inter American Commission on Human Rights, the Guatemalan government took responsibility for the journalist's disappearance and reopened the case. The reconstruction of memory through narrative techniques not only resulted in remembering history, but in changing it.

\section{Keywords}

Human Rights • Guatemala • Journalism

\footnotetext{
* June is Publications Director at Harvard's David Rockefeller Center for Latin American Studies, and editor-in-chief of ReVista, the Harvard Review of Latin America. Author of Disappeared, A Journalist Silenced: the Irma Flaquer Story (Seal Press, 2004), she is currently on sabbatical with a Fulbright Fellowship in Bogotá, Colombia.
} 
Talvez ningún otro país tenga una historia tan documentado de sus días oscuros como Guatemala, un país centroamericano con 15 millones de habitantes, menos que la región metropolitana de São Paulo. ${ }^{1}$ Después de una guerra interna y cruenta con duración de 36 años, fueron firmados los Acuerdos de Paz entre el gobierno y la guerrilla en 1996. Más de 200,000 personas murieron en el conflicto en este pequeño país, y aproximadamente 50,000 personas fueron desaparecidos para siempre. Talvez en ningún país, ha habido tanto esfuerzo para recompilar narrativas y testimonios, rompiendo con la cultura del silencio y la cultura del miedo.

Antes de la firma de los Acuerdos, ya funcionaba la Comisión (CEH), trabajando bajo los auspicios de las Naciones Unidas ${ }^{2}$. Y, casi al mismo tiempo, pensando que el informe del CEH no iba a ser lo suficientemente duro, comenzó a funcionar una comisión de la iglesia para documentar los horrendos abusos de los derechos humanos: Recuperación de la Memoria Histórica (REHMI). ${ }^{3}$ Muchos fueron sorprendidos cuando la CEH publicó su informe en 1998, examinando no solamente los abusos, sino también sus causas.

"La CEH concluye que fenómenos coincidentes con la injusticia estructural, el cierre de los espacios políticos, el racismo, la profundización de una institucionalidad excluyente y antidemocrática, así como la renuencia a impulsar reformas sustantivas que pudieran haber reducido los conflictos estructurales, constituyen los factores que determinaron en un sentido profundo el origen y ulterior estallido del conflicto armado", observó el documento.

"Después del derrocamiento del Gobierno del coronel Jacobo Arbenz
en 1954 tuvo lugar un acelerado proceso de cierre de espacios políti-
cos, inspirado en un anticomunismo fundamentalista que anatemizó
un movimiento social amplio y diverso, consolidando mediante leyes
el carácter restrictivo y excluyendo del juego político. Estas restric-
ciones a la participación política fueron pactadas por diversos secto-
res de poder fáctico del país y activadas por las fuerzas civiles y polí-

\footnotetext{
${ }^{1}$ La cifras de población están tomadas de http://www.cia.gov/cia/publications/factbook/geos/ gt.html (para Guatemala) y http://www.bartleby.com/65/sa/SaoPaulo.html (para São Paulo).

${ }^{2}$ Comisión para el Esclarecimiento Histórico (CEH), 1998.

${ }^{3}$ Informe del Proyecto Interdiocesano de Recuperación de la Memoria Histórica Guatemala: Nunca Más, 1999.
} 
ticas de esta época. Este proceso constituye en sí mismo una de las evidencias más contundentes de las estrechas relaciones entre el poder militar, el poder político y partidos políticos surgidos en 1954. A partir de 1963, además de las restricciones legales, la creciente represión estatal contra sus reales o supuestos opositores fue otro factor decisivo en el cierre de opciones políticas en Guatemala". ${ }^{4}$

En la Centroamérica de la década del 80, nadie era inmune a la violencia. En Guatemala, mucha gente pensaba que las noticias de masacres y asesinatos eran muy exageradas o eran actos de delincuentes comunes. Había quien veía la violencia como el desafortunado, pero necesario, intento de salvar al país de los "terroristas comunistas". El informe de la CEH, y después el del REHMI, rompió con esa imagen, ayudó a esclarecer la memoria y a comenzar con un proceso a través del que la gente podía hablar y recordar libremente.

La CEH constató que las fuerzas estatales y grupos paramilitares afines fueron responsables del 93\% de las violaciones documentadas.

Así, cuando el Informe REHMI salió un año después, sirvió para colaborar y fortalecer las investigaciones de la $\mathrm{CEH}$. Este informe analizó varios miles de testimonios sobre violaciones de los derechos humanos ocurridas durante el conflicto armado interno. "Este trabajo está sustentado en la convicción de que, además de su impacto individual y colectivo, la violencia quitó a los guatemaltecos su derecho a la palabra," observó una resumen del documento.

"Cada historia es un recorrido de mucho sufrimiento, pero también de grandes deseos de vivir. Mucha gente se acercó para contar su caso y decir 'créame'. Esta demanda implícita está ligada al reconocimiento de la injusticia de los hechos y a la reivindicación de las víctimas y sus familiares como personas, cuya dignidad trató de ser arrebatada". 5

No es casualidad de que ambos informes utilicen la palabra "memoria". La memoria cumple su papel como instrumento para rescatar la identidad colectiva, combatir la impunidad y reconstruir la historia. Pero un factor que los informes REHMI y CEH tenían en común es que el enfoque está en las víctimas,

\footnotetext{
${ }^{4}$ Comisión para el Esclarecimiento Histórico (CEH), 1998, p. 34.

${ }^{5}$ Comunicado de Prensa, Informe del Proyecto Interdiocesano de Recuperación de la Memoria Histórica Guatemala: Nunca Más, febrero 1999.
} 
como objetos de crímenes atroces, que subrayaban la muerte, y no en las vidas perdidas. Esos informes compartían el mandato de informar sobre las víctimas y los abusos a los derechos humanos. Además, aunque los informes asignaron culpa a grupos tal como los guerrilleros o grupos estatales o paramilitares, no buscaban asignar responsabilidad individual o comenzar un proceso formal contra la impunidad. El proceso consistía en - una vez roto el silencio - estimular y fortalecer la memoria colectiva y escribir la historia.

Soy periodista, profesora de periodismo y editora, no historiadora. Cuando la Sociedad Interamericana de Prensa (SIP) me pidió en 1996 actuar como investigadora en su proyecto, "Crímenes Sin Castigo contra Periodistas", no podía imaginar el papel de la memoria en la construcción de la historia y en la búsqueda del fin de la impunidad. ${ }^{6}$ Es cierto. Como periodista, siempre he puesto mucha énfasis en la narrativa, y como lectora, he encontrado que son los detalles de la historia los que nos quedan en la mente y estimulan la acción. Así fue como la historia de Anne Frank iluminó el Holocausto con su narrativa de esperanza y amor juvenil, y que los miles de reportajes cortos sobre las vidas de las víctimas en el New York Times, después del ataque a las torres gemelas, estimularon muchos actos de solidaridad.

Pero, cuando fui asignada al caso de la guatemalteca Irma Flaquer, una periodista valiente quien fue desaparecida en 1980, solamente pensé en resolver el caso en términos periodísticos y redactar un informe sobre el mismo. No esperaba que la vida de la periodista me cautivara, y en el proceso, captar la imaginación de muchos otros, que también se interesaron en el caso. Estaba pensando en la memoria, es cierto, pero en el sentido de hacer con que la gente, a través de entrevistas, recordase y confesase lo que había pasado con Irma Flaquer.

Desde 1958, Flaquer trabajó como periodista para diversos diarios, iniciando su columna "Lo que otros callan" en ese mismo año y continuando casi hasta su secuestro en 1980. No fue ese el único atentado contra ella. En 1960, cuando tenia solamente 22 años, un grupo de mujeres del mercado - que muy frecuentemente buscaba empleo extra, participando en bandas, promovidas por el gobierno, para reprimir ilegalmente opositores - la golpearon hasta dejarla inconsciente en la calle. En 1969, fue víctima de un carro-bomba que

\footnotetext{
${ }^{6}$ Para más información, vea a www.impunidad.com.
} 
casi le quitó la vida. Como consecuencia, durante el lapso de un año, fue sometida a operaciones quirúrgicas. A pesar de amenazas constantes, siguió escribiendo sobre la corrupción, los derechos de mujeres, indígenas y sindicalistas, como así también sobre los abusos a los derechos humanos. No sabía callarse. No quería callarse.

Al principio, vi a Flaquer como una víctima, una de las muchas víctimas que, en un par de años, serían documentadas en los informes de la CEH y REHMI, o en los informes constantes de la SIP, o del "Comité para Proteger a Periodistas" cuya preocupación principal eran los crímenes contra periodistas. Yo sabía - y se - los números.

Entre 1995, el año antes de comenzar mi investigación sobre el caso de Irma Flaquer, y el año pasado, cuando publiqué mi libro sobre Irma Flaquer ${ }^{7}$, 341 periodistas han sido asesinados en el cumplimiento de sus tareas. ${ }^{8}$ Pero en todo este tiempo, solamente hay 35 casos en que la persona o personas, que ordenaron los asesinatos, han sido detenidas y juzgadas. Es decir, en $85 \%$ de los casos los responsables continúan en la impunidad.

El caso de Irma Flaquer me enseñó que ni la impunidad ni la historia se tratan de números. Irma Flaquer me enseñó lo que es ser periodista y luchar contra la impunidad, luchar a veces en vano hasta ser víctima de la misma impunidad. Uno de los casos más citados por los guatemaltecos fue un doble asesinato cometido a la luz del día en el restaurante "El Pescador". Tres adolescentes estaban celebrando después de un partido de fútbol, cuando los guardaespaldas de un una persona rica les ordenó callar. Uno de los jóvenes contestó, "Porque? Estamos en un país libre." Los guardaespaldas se fueron, pero regresaron en algunos minutos, disparando contra los muchachos. Dos de los jóvenes murieron.

Para la periodista Irma Flaquer, el caso de los hermanos Pais Maselli llegó a ser una prueba para constatar si la democracia podría funcionar. Ella luchó para que se hiciera justicia en ese caso, no contra los guardaespaldas, pero si contra ese hombre de negocios rico, Jorge Kóng Vielman, quien había ordenado la matanza. Para la periodista, y para los muchos guatemaltecos que

\footnotetext{
${ }^{7}$ ERLICK, June; EMERYVILLE, CA. Disappeared, A Journalist Silenced: The Irma Flaquer Story, 2004.

${ }^{8}$ Comité para Proteger a Periodistas, Nueva York, informe, 2005.
} 
siguieron el caso, fue algo emblemático: la oportunidad de comprobar que Guatemala era un país de derecho. Jorge Köng fue sentenciado por la Corte a ocho años y ocho meses de cárcel. Escribió Flaquer:

(A)1 firmar la sentencia el juez reivindicó a la justicia guatemalteca por largo tiempo desprestigiada al extremo de que ya nadie creía que en realidad la justicia tuviese una venda en los ojos, La sentencia que comento es una prueba de que sí la tiene. De que no importa que el acusado sea rico, poderoso, y con relaciones importantes y muy influyentes. Si hay pruebas de que cometió un crimen se aplica la ley y se cumple con la obligación aunque al hacerlo se pierda la tranquilidad. En otro artículo comentaba el peligro gravísimo que estamos corriendo ante la semilla de violencia que representa el no confiar en los tribunales. La primera consecuencia es que muchos decidan hacerse justicia por su propia mano ya que no puede contar con los encargados de administrarla lo hagan imparcialmente.

Hasta la fecha no hay quien afirme que en los tribunales hay una corrupción descarada, invencible. Que los ricos y los influyentes salen libres aunque hayan cometido el peor de los delitos. Mientras que los pobres están fatalmente destinados a pudrirse en Pavón hasta por hurtar un pan para sus hijos.

Esta convicción es la verdadera madre de la violencia. No sólo porque el ciudadano se siente desamparado y ve en los tribunales, jueces, oficiales y abogados a enemigos acérrimos, sino también - y lo más peligroso - porque siente que, mientras él es tratado como un enemigo de la sociedad, hay en cambio un grupo de personas, una élite, una clase, que puede cometer atropellos y hasta delitos grandes sin que nadie los toque, mucho menos los tribunales.

La sentencia contra Köng es, por lo tanto, un beneficio precedente en nuestro país que tan necesitado está de la confianza de toda la ciudadanía en la recta administración de justicia. ${ }^{9}$

Leyendo las columnas de Flaquer y entrevistando a colegas, me di cuenta de su extraordinaria confianza en que Guatemala podría efectuar un cambio a través de la sociedad civil y el estado de derecho. Al mismo tiempo, recorda-

\footnotetext{
${ }^{9}$ Irma Flaquer, "Los que Otros Callan,” La Nación, 14 de septiembre, 1977.
} 
ba - o aprendía - que durante todos los años de la guerra civil, existía esa otra tendencia que muestra que la historia consiste no solo en víctimas y violencia, sino también en agentes activos de la sociedad civil, como Flaquer, quien creía en la transformación pacífica del país.

Era una posición difícil de sostener porque los agentes activos de ese cambio pacífico fueron matados, como si fueran guerrilleros. Hasta las pequeñas victorias se iban acabando.

Como suele pasar en países en que la democracia es solamente una palabra, la victoria que Flaquer experimentó en su cruzada para que se hiciera justicia contra Köng no duró mucho. Muy poco después de la sentencia de los tribunales, Köng fue liberado por una tecnicidad.

Este fracaso de la justicia guatemalteca no fue una tragedia únicamente para una familia en un punto concreto de la historia. La impunidad sigue y cosecha más impunidad. Fue un fracaso para toda la sociedad. Y como Irma Flaquer vio claramente, la impunidad no puede existir - no debe existir - en un estado de derecho. En 1996, en un país dividido entre la paz y la guerra, entre un estado de derecho y un estado de caos, era significativo reconstruir y recordar la voz civil de Irma Flaquer. Evocar su memoria significaba activar la memoria de aquellos que actuaban con consciencia y recordar que la historia está llena de agentes activos y no solamente de víctimas.

Sin embargo, siguiendo mis investigaciones, encontré que mis preguntas evocaban memorias mucho más complejas: las de una mujer frágil que le temía a la muerte; de una periodista tan idealista que a veces se metía en la política; de alguien a quien le encantaban los quesos y las longanizas y siempre estaba tratando de no engordar; de una mujer que tenia las uñas largas y bien cuidadas, a pesar de su constante uso de la maquina de escribir.

Al principio, tomé los muchos detalles de su vida como anécdotas graciosas que a la gente le gustaba contar, y no como cosas significantes. Pero, de repente, me di cuenta que la memoria de los detalles que pintaban a Irma Flaquer como un ser humano vulnerable - ni heroína ni víctima - ayudaba a mis interlocutores a recordar los detalles de su crecimiento político y reconstruir la historia de una manera menos polarizante. La memoria de lo cotidiano ayudó a recuperar la historia, rompiendo con el hábito de silencio.

Comencé a darme cuenta que en una sociedad en la cual recordar es peligroso, no se desarrolla una memoria política compartida. Pero al mismo tiempo, la gente sigue viviendo, comiendo, participando en fiestas religiosas, escu- 
chando música. Este tipo de memoria, la que algunas llaman "cultura inmaterial” sigue a pesar de la represión de la memoria más politizada.

"Por ser inmaterial es la memoria viva que tienen las personas y que
se transmite oralmente y compartiendo en la práctica, por esto crea
afectos, lazos de amistad y de solidaridad, lo que nos da la seguridad
de ser parte de una comunidad con la que construimos una historia
conjunta. De aquí su importancia en la identidad", observó reciénte-
mente la antropóloga colombiana Ana María García López. ${ }^{10}$

En una sociedad que había sido polarizada por tanto tiempo, la técnica de la narrativa ayudó a reconstruir una memoria, que construía la historia de Irma Flaquer con matices. El retrato de ella también reflejaba la ambigüedad de su fin: ella estaba tanto en la lista negra del estado, como en la de la guerrilla. Más y más, vi su historia como la historia de una vida, y no de una víctima. No pude resolver el caso, y cuando entregué mi informe a la SIP, sentí que había fracasado.

El informe detalló la lucha de Irma Flaquer como periodista contra la impunidad y a favor de la libertad de prensa. También, describió su vida de mujer como esposa, madre, mujer divorciada, amante, abuela, editora, periodista, abogada y psicóloga. Examinó las angustias de su familia y colegas a perderla, además de las diferentes teorías sobre su desaparición.

Pensé que era el fin del proyecto. Pero la figura de Irma Flaquer me intrigaba y, cada vez que podía, viajaba desde Harvard a Guatemala a seguir entrevistando más gente. Y comunicaba mis hallazgos siempre a la SIP, especialmente a Ricardo Trotti, un joven y enérgico argentino quien dirigía el proyecto contra la impunidad. Trotti, quién también es un pintor de mucho talento, se contagió de mi pasión por el caso. Hasta pintó un cuadro titulado "Las Tres Irmas y Su Hijo". ${ }^{11}$

\footnotetext{
${ }^{10}$ Ana María García López, "Herencia compartida y memoria viva”, Boletín, Ministerio de Cultura, septiembre de 2005.

${ }^{11}$ Flaquer, además de periodista, había hecho las carreras de psicología y derecho, así "las tres Irmas". Su hijo, Fernando, fue matado a balazos cuando la periodista fue secuestrado.
} 
Trotti me había dicho una vez que, de todos los informes hechos en el contexto del proyecto "Crímenes sin Castigo contra Periodistas", el mío era el único que había retratado a la víctima.

Para mi sorpresa, el caso fue el primero que la SIP llevó a la Comisión Interamericana de Derechos Humanos.

"El sistema judicial del país, por su ineficacia provocada o deliberada, no garantizó el cumplimiento de la ley, tolerando y hasta propiciando la violencia. Por omisión o acción, el poder judicial contribuyó al agravamiento de los conflictos sociales en distintos momentos de la historia de Guatemala. La impunidad caló hasta el punto de apoderarse de la estructura misma del Estado, y se convirtió tanto en un medio como en un fin. Como medio, cobijó y protegió las actuaciones represivas del Estado así como las de particulares afines a sus propósitos, mientras que, como fin, fue consecuencia de los métodos aplicados para reprimir y eliminar a los adversarios políticos y sociales" ${ }^{\prime \prime}$,

insistió la SIP en su queja frente a la Comisión.

Con el caso frente a la Comisión, decidí pedir una beca Fulbright para ir a Guatemala de nuevo para convertir la historia de Irma Flaquer en un libro, y consolidar todas las memorias en una forma permanente. El resultado fue, "Disappeared, A Journalist Silenced: The Irma Flaquer Story"por fim publicado en 2004.

Pero, antes, el 2 de marzo de 2001, en Washington DC, el gobierno de Guatemala llegó a un acuerdo de solución amistosa con la SIP, bajo el auspicio de la Comisión Inter Americana de Derechos Humanos, poniéndose de acuerdo en "iniciar un proceso de negociación, para establecer orientaciones y mecanismos tendientes a resolver dicho caso dentro del marco de la solución amistosa". ${ }^{13}$

Alfonso Portillo Cabrera, el presidente guatemalteco, reconoció la responsabilidad institucional del Estado en el caso de Flaquer:

\footnotetext{
${ }^{12}$ Vea www.impunidad.org para una historia más completa del caso.

${ }^{13}$ Acuerdo Amistoso, firmado el 2 de marzo, 2001, en Washington DC.
} 
"El Estado deplora y reconoce como deleznable la desaparición forzada de la periodista Irma Marina Flaquer Azurdia, acaecida el 16 de octubre de 1980, y sustenta el criterio acerca de la imperiosa necesidad de proseguir y reforzar firmemente las acciones administrativas y legales orientadas a establecer la identidad de los responsables, establecer la localización de la víctima, así como la aplicación de las correspondientes sanciones penales y civiles".

El acuerdo continua a decir que

"El Estado reconoce el compromiso de otorgar las reparaciones que se acuerden con la parte peticionaria. En este sentido, adquiere el compromiso de estudiar y considerar el pliego de peticiones que por concepto de reparaciones le fuera planteado por los Peticionarios, vinculadas todas ellas al nombre de Irma Marina Flaquer Azurdia". ${ }^{14}$

El acuerdo enfocó en parte medidas de resarcimiento: admitir la responsabilidad del estado; pagar miles de dólares en reparaciones a la familia; reabrir el caso y nombrar un fiscal especial para investigarlo, y hacer un esfuerzo de encontrar los restos de la periodista. Como el CEH y el REHMI, mencionados anteriormente, como esfuerzos para establecer la verdad a través de testimonios y narrativas, el informe de la SIP inspiró la queja, resultando en acciones concretas y, uno podría decir, históricas.

Pero, más que una admisión de culpabilidad con las debidas reparaciones, el acuerdo amisto entre el gobierno de Guatemala y la SIP reconoció la importancia de la memoria como parte de la resolución del caso.

Uno de los puntos del acuerdo fue la creación de una beca de estudio para periodismo, que lleva el nombre de Irma Flaquer, y es eventualmente otorgada por el Programa de los Naciones Unidos para el Desarrollo (PNUD) en Guatemala. Esa beca permite a periodistas jóvenes y talentosos hacer pasantías en otros países. Es una forma de recordar los ideales de Flaquer, y hacer que su nombre y su trabajo sean conocidos en las salas de redacción guatemaltecas.

Otros puntos - incluidos en una categoría que podría llamarse "servicios en nombre de la memoria" - incluyen la creación de una sala para la paz en la

\footnotetext{
${ }^{14}$ Acuerdo Amistoso, firmado el 2 de marzo, 2001, en Washington DC.
} 
biblioteca de la Universidad de San Carlos; el desarrollo de cursos de capacitación y reinserción social destinado a las reclusas del Centro de Orientación Femenino (COF, la cárcel de las mujeres), porque Flaquer trabajaba con presas y escribió con frecuencia sobre las injusticias sufridas por ellas.

También, hay en el acuerdo una categoría que se refiere a la divulgación del trabajo de la periodista. En cumplimiento de ese acuerdo amistoso, un documental fue hecho sobre su vida y trabajo, y un volumen con columnas, escritos y reportajes, que representen el mejor sentido periodístico de la desaparecida periodista, fue publicado bajo el nombre "La que nunca calló".

El acuerdo enfatizó "la dignificación” de Irma Flaquer, ordenando la erección de un monumento al periodista sacrificado por el derecho a la libre expresión, simbolizado por la personalidad de Irma Marina Flaquer Azurdia; la calle donde ella vivía en el centro de Guatemala fue bautizada con su nombre; también el acuerdo estableció el mandato de "realizar un acto público de dignificación [...] estableciéndose de antemano la fecha del 5 de septiembre del 2001 - natalicio de la desaparecida periodista - para realizar un acto público, con las partes involucradas, en la Ciudad de Guatemala".

Repasando la lista de los acuerdos, pensé al principio que era demasiado periodística, demasiado descriptiva, para ser incluida en este ensayo: siempre el desafío cuando una periodista trata de entender historia. Pero esta vez, me encontré involucrada en la construcción de la historia. Examinando la lista de los acuerdos, encontré una estructura de categorías diversas que me ayudó y nos ayuda - a entender como la memoria a través del proceso de reconstrucción de narrativas se convierte en historia o, por lo menos, una historia recordada y perpetuada.

La primera categoría, la de las reparaciones, en cierto sentido, cambia la historia. El discurso del Estado de Guatemala había sido por casi 40 años un discurso sobre el bien y el mal, en que el gobierno y sus aliados eran los buenos, combatiendo a los malos: terroristas, comunistas y subversivos. Por ejemplo, en el caso de la Embajada de España, aunque el propio embajador pidió la no-intervención, el gobierno justificó sus acciones en nombre de su compromiso de acabar con la subversión, que utilizaba como táctica la toma de embajadas y universidades. Aún en la muerte, las víctimas continuaron siendo los malos, con el gobierno acusándolos de haber tirado cócteles Molotov para encender el fuego que causó sus muertes. 
Después del caso de la Embajada de España, el gobierno de ese país rompió relaciones diplomáticas con Guatemala; la Embajada de los Estados Unidos debido a la relación amistosa entre los dos embajadores - asistió el embajador español, pero nunca tomó una posición clara frente al caso, y el embajador Frank Ortiz fue transferido un poco después. El estatus de Guatemala como un luchador sólido y un aliado firme en la batalla entre Oeste y Este siempre fue más importante que la perdida de vida. Y aunque el mundo de organizaciones nogubernamentales e iglesias siempre protestaron contra los abusos de los derechos humanos - de los cuales, la embajada de España era emblemática - el resto de la comunidad internacional mantuvo un silencio relativo.

Así, con la admisión de culpa por la negligencia en el caso de Irma Flaquer, varias cosas están pasando. Primero, el gobierno de Guatemala salió del parámetro del bien y del mal. A pesar de la posición política de Flaquer, el gobierno tenia la obligación de protegerla como una figura pública, según las convenciones internacionales, como periodista destacada y como fundadora de la primera Comisión de Derechos Humanos Guatemalteca.

Segundo, Guatemala aceptó su responsabilidad como Estado, no como Gobierno. No fue el gobierno de Alfonso Portillo, el presidente guatemalteco en 1996, que hizo desaparecer a Irma Flaquer. Fue durante el régimen del General Romeo Lucas García. Al llegar a un acuerdo amistoso, el gobierno aceptó la responsabilidad de Estado, es decir, la responsabilidad de la historia, que dice que la culpabilidad no se acaba cada cuatro años con el presidente de turno.

Tercero, el pago de reparaciones - varios miles de dólares - a la familia, mostró el compromiso de que la admisión de culpabilidad no quedará en puras palabras. También, cambió la trayectoria a nivel personal, al modificar las historias personales de la familia de Irma: por ejemplo, su hijo sobreviviente Sergio pudo conseguir rehabilitación para sus alcoholismo y su nieto Alejandro pudo estudiar ingeniería civil en la universidad.

Cuarto, el compromiso de la Sociedad Interamericana de Prensa y de la Comisión Interamericana de Derechos Humanos muestra el nuevo papel de las organizaciones internacionales en la historia de hoy.

Quinto, el punto en que el gobierno ha sido más lento, y tal vez más deficiente, es en el reconocimiento del hecho que, como no hubo un proceso de derecho en el momento de la desaparición de Irma Flaquer, ese compromiso existe ahora. Así, el gobierno oficialmente reabrió el caso y asignó un fiscal especial y, al mismo tiempo, prometió hacer un esfuerzo especial para buscar sus restos. 
Después de cuatro años, no se han hallado los culpables ni se han encontrado los restos de la periodista desaparecida. En una lectura de Disappeared, A Journalist Silenced en la ciudad de Washington DC en febrero de 2005, un funcionario guatemalteco comentó que el caso es bastante viejo y que el gobierno guatemalteco no tiene los recursos de la FBI ni la CIA.

Eso puede ser cierto, pero el gobierno de Guatemala adquirió un compromiso frente a la Comisión de Derechos Humanos. Además, en julio de 2005, los archivos secretos de la Policía Nacional fueron descubiertos en la Ciudad de Guatemala. Muchos creen que esos documentos contienen información sobre los desaparecidos. En el contexto del acuerdo, el gobierno tiene que dar prioridad al caso de Irma Flaquer, como un caso ejemplar que muestra que los crímenes no puedan seguir con impunidad, que el gobierno acepta su responsabilidad de Estado, no solamente con palabras, pero con justicia. Así, el acuerdo puede cambiar y, de hecho, ha cambiado hasta la fecha, la historia.

Las otras categorías del acuerdo - servicios, divulgación, y dignificación llevan los ideales de la periodista a diferentes constituyentes: periodistas, presas, estudiantes, lectores, transeúntes. Uno puede preguntarse cuantas veces ha pasado en una calle sin reparar en su nombre (que generalmente es un segundo nombre de conmemoración) y cuantas veces ha pasado un monumento sin fijarse en su dedicación. Pero, como conjunto, todos esos actos sirven para poner el nombre de la periodista - como símbolo de la prensa libre y la lucha contra la impunidad - en la esfera pública, a asumir un lugar en la historia, un claro rompimiento con la cultura del miedo, la cultura del silencio. Además, tienen el efecto de pasar la memoria de una generación a la otra, es decir, realmente convertir las memorias, las narrativas, en historias.

De todos los actos de dignificación, el más conmovedor fue la misa en la Catedral de la Ciudad de Guatemala el 5 de septiembre de 2001, seis días antes de que el ataque contra las torres gemelas le enseñara al pueblo norteamericano el significado de tener desaparecidos. Solamente había un retrato de Flaquer donde debía reposar un cadáver. Pero era la primera vez que la muerte de la periodista era reconocida en público y representaba una clausura emocional para muchos miembros de la familia, amigos y colegas. La misa también representaba ese acto de transmisión de generación en generación. Habló Viana de Maza, una sobrina de la periodista:

Yo tenia solamente dos años cuando fue secuestrado Irma...Irma, aunque no estuviera allí, siempre fue parte de mi vida. Yo había oído 
de ella, pero no fue hasta recién que tuve la oportunidad de leer lo que ella había escrito. Un día, regresé a la casa, y mi madre tenía en el comedor algunas fotocopias que me llamaron la atención. Comencé a leer y no pude parar. Era un libro que Irma había escrito y me dio escalofrío. También leí algunas de sus columnas.

Fue en ese entonces que me di cuenta de quien había sido mi tía: su inteligencia, su capacidad, su talento, y, sobre todo, su valentía incrementó mi admiración por ella, y comencé a identificarme con ella...Es muy importante que una mujer pueda lograrlo todo como lo logró ella [...] ver sus fotos y ver [que] bella fue ella y al mismo tiempo saber que su sangre corre en mis venas [...]

Somos los hijos de la guerra. Somos los hijos e hijas de esa cantidad de maldad que ahogó nuestro país por tanto tiempo. No es fácil. Me imagino que no fue fácil vivir durante la guerra, pero ahora tenemos una tarea doble. Tenemos una amargura que es muy difícil de manejar. Es algo que hemos aprendido, pero al mismo tiempo, no la sentimos directamente.

Tengo un grupo de amigos. Nuestro grupo consiste en el hijo de un guerrillero, el hijo de un comandante guerrillero, la hija de una pareja exiliada, el hijo de algunos hippies, la hija de alguien que no tenia ni idea que una guerra estaba pasando—es decir, los hijos de gente que no se podía ver....Creo que las cosas están cambiando, y si no han cambiado, van a cambiar y queremos que cambian....

Estoy enamorada de mi país y quiero lo mejor para su gente. Estamos tratando de hacer lo más que podemos con nuestros pobres recursos y creo que la juventud es uno de los más importantes recursos hoy día...Yo no tengo miedo de hablar, y creo que eso es el regalo más grande que Irma me ha dejado. ${ }^{15}$

Así es, que en la Catedral de Guatemala, después de 20 años de silencio, las generaciones se juntaron a conmemorar Irma Flaquer, transformando una narrativa personal en historia e acción social.

La guatemalteca Marta Elena Casaús Arzú resume el proceso así:

${ }^{15}$ Discurso de Viana de Maza, 5 de septiembre, 2001, transcripción de una grabación. 
"Entre la historia personal y la historia de una generación, es en términos gramscianos el momento catártico de toma de conciencia colectiva de toda una generación de que las cosas ya no son lo que eran, de que a partir de ese momento hay un antes y un después; en otras palabras, nuestra identidad queda marcada a partir de entonces." ${ }^{16}$

Ya Irma Flaquer forma parte de la identidad e historia guatemalteca, un caso emblemático y un símbolo contra el silencio.

Recebido em 06/10/2005 e aprovado em 25/10/2005.

${ }^{16}$ Marta Elena Casaús Arzú, "Las huellas de la violencia: La masacre de la embajada de España en Guatemala", http://www.memoria.com.mx/153/Casaus.htm. 